\title{
Strategic Shift from Transmissive to Transformative Higher Education for Sustainable Development
}

Mohamed Jama Madar, Hikma Center for Research and Training, University of Hargiesa Mustafa Din Bin Subari, Universiti Teknologi Malaysia, Malaysia Shadiya Mohamed Saleh Baqutayan, Universiti Teknologi Malaysia, Malaysia

\begin{abstract}
Education for Sustainable Development (ESD) is a global initiative towards transforming education for sustainability. The integration of SD into the education portfolio is considered to be an important approach that ensures strategic alignment of higher education with SDGs. A document review was used to identify and discuss the difference between transmissive and transformative education in relation to SDGs and in the context of Somali education. In this trajectory, it is expected that the concept of "transformative education is likely to become more common to meet the emerging social, economic and environmental issues, yet practical challenges remain in Somaliland HE sector. The roadmap towards addressing transformative education for sustainability is not included in the Somaliland national portfolios; particularly ESD has not been presented. In this regard, this paper proposed a generic framework that spotlights the integration of HEIs and the national development goals (NDGs) in Somaliland.

Meanwhile, developed and developing countries are prioritizing structural transformation in their HEIs that are tailored to national and regional development programs. Consistent with the Rio +20 outcomes, the authors analyzed the concept of the "sustainable university" and identified the fact that it is practically divided into three interrelated and complementary categories, namely social-, environmental-, and economic-oriented university in pursuit of actualizing SD. The paper recommends major reforms in the education sector including availing investment portfolios for $\mathrm{R} \& \mathrm{D}$, renovation of education goals and transforming universities for sustainability
\end{abstract}

Keywords: ESD, Transformative Education, Transmissive Education, SDGs, HEIs

\section{Introduction}

Following the global declaration and political commitment to Sustainable Development Goals (SDGs) during the Earth Summit in 1992, Education for Sustainable Development (ESD) has become a major concern within Higher Education Institutions (HEIs). The scheme of ESD came into the global agenda in 1990, where HEIs leaders from 320 universities in 47 countries pledged the Talloires Declaration for Environmental Sustainability [1]. These declarations and other subsequent summits obligated HEIs to respond to the pivotal sustainability endeavors. Due to the awakening calls for sustainability and the challenges posted by the global dynamics necessitated HEIs to shift and become more transformative. Furthermore, HEIs were offered to adapt the Higher Education Sustainability Act and the United Nations Decade of Education for Sustainable Development (DESD) in 2005-2015 [2]. The UN DESD (2005 to 2015) provides a major opportunity for HEIs worldwide to address sustainability at local, national, regional and global levels [3]. Besides, ESD is an educational goal that aims to provide the present generations with the necessary knowledge, skills, competencies, and values that are crucial for societal sustainability [4].

On the other hand, the concept of sustainability is both complex and overlapping since it incorporates economic, environmental, and social aspects. As such, there is a need to propose 
and develop comprehensive directions for HE in Somaliland so that they muddle through the sustainability challenges. On top of that, developing global framework for ESD as a policy benchmark is crucial for holistic solutions to the current sustainability challenges [5]. Then, there is to transform universities in way that contributes to the targets of SDGs and find durable solutions to the sustainability challenges for the present and the future generations [6]. The declaration of DESD by UNESCO advised to all educational sectors of society to develop and deliver the programs of ESD by integrate sustainability elements into their provisions [7].

The ESD initiatives enabled HEIs to position and restructure their education portfolios in the direction of more transformative programs tailored to the SDGs. In this regard, HE must respond to the social dynamics within the features of sustainability powered by the increasing demand for life changing knowledge, skills and attitudes [8]. However, a fruitful strategic change in HE requires a transformational leadership as well as collaborative efforts amongst the key actors and stakeholders including; private business, government and civic institutions [9]. Since, the targets of SDGs are meet the needs for the present and the future generation; any outcome of educational programs shall be an indicator for the sustainability dimensions [10]. Additionally, education institutions ranging from primary to university levels ought to adapt more transformative education design rather than ensuring only transmissive role.

In view of that, HEIs should demonstrate a transformative role in fostering the society and finding durable solutions for sustainability challenges [2]. In Somaliland context, all endeavors of SDGs are tailored to the National Education Plan into some extent but are not planned and coordinated in a contextual approach but are rather circumstantial interventions. Nonetheless, the responsibility to lead and ensure whether SDGs are being implemented goes to government institutions in collaboration with companies, professional bodies, education and research institutions [11].

The concept of SD has been gaining a well-deserved recognition over the past decades, proving to be the path to towards a genuine social and economic development [12]. One particular factor is that the quality of the human capital has proven to be the most important condition for a successful transition towards a sustainable model of development [13]. Therefore, building human capacity is not more than establishing education system that promotes transformational change in human life cycle through $21^{\text {st }}$ century curriculum framework. Finally, this review paper will spotlight status of $\mathrm{HE}$ in Somaliland and propose key recommendations on the strategic turning points.

\section{Education for Sustainable Development in Somaliland}

In Somaliland context, the process of drafting ESD is now a major concern as there are no such plans set for guiding HEIs toward sustainability endeavors. The current Somaliland National Development Goals and the wider Somali states lack the sustainability portfolios in relation to their national priorities. The lack of ESD as a national strategy is the fact that burden HEIs' 
sustainability initiatives as numerous challenges ahead. HEIs in the Somaliland context need reform in the areas related to SDGs and structure their educational programs based on the fundamental principles of ESD. Important step in demonstrating institutional commitment towards SD in HEIs is endorsement of Declarations on Sustainability in HE [14]. These declarations are not conceptually addressed in SNDGs as well as the current Education Sector Plan (ESP). Therefore, the operationalization of SDGs targets within the SNDGs still remains unmeasurable let alone to analyze the impact.

Among the problems Somaliland Education Program facing are the issue of the educational goals mismatch with the direction of the country's economic development. In case of Somaliland, education calls for the expansion of the country's supply of SDGs provisions, with a specific focus on industrial development and STI [15]. In spite of the number of development initiatives within SNDGs, yet increasingly all universities in Somaliland are engaged in transmissive education without any accreditation and standards. While there is an indispensable need for HEIs adapts a transformative approach, yet there are sparking issues pertaining to relevance and quality of education. As a result, many universities in Somaliland like any other underdeveloped world are still lagging behind the syndicates in helping societies become more sustainable with economic prosperity and social well-being. For centuries, universities have been at the forefront in creating and breaking paradigms, and educating the future decision-makers, entrepreneurs, and leaders. However, universities in Somaliland have remained to be small in capacity and competency in relation to addressing the SDG targets let alone to act as a transformative icon.

Many educationist and researchers strongly suggested that curriculum innovation is the essential vehicle for the implementation of ESD in universities [16]. While education institutions are the drivers and factories that produce the knowledge and skills required to boost the economy, nonetheless, they are not the only entities obligated to undertake this role. Similarly, corporates, small enterprise should also integrate SD into their social responsibilities [17]. Private sectors also play a shaping role in the development of SDG agenda, which potentially offers, improved social, economic and environmental impacts [17]. As all levels of education are integral part in social well-being, this paper emphasizes on the potential role of HEIs in achieving SDGs. With respect to the contemporary university generations, students are being prepared to enter the labour market and emerge with skills to support the SDGs and share their knowledge and innovative ideas. Increasingly, universities and other professional bodies have been incorporating on SD values and practices into their core activities including their institutional management and operational systems [18]. However, the debate thus far has focused primarily on the rationale and reasoning for why Somaliland needs broad SD adoption. The international discussions, however, has failed to specify the various frameworks that HEIs can adopt so as to respond to the SD dimensions. However, this paper emphasizes more on integrating HESD into the strategic decisions at the national, regional and global levels.

In addition, the vision of ESD is a global initiative, where everyone has the opportunity to benefit from quality education and learn the values, behaviors and lifestyles required for a 
sustainable future and for positive societal transformation. Nevertheless, Somaliland education system does not follow the $21^{\text {st }}$ century education framework which is tailored to the SDGs and its inventory of skills. Finally, if the education system is to create a difference in social, economic and environmental aspects, the current education in Somaliland might not able to fit the marketplace demands let alone to be transformative and SDGs oriented.

\section{Transforming HEIs for Sustainable Development in Somaliland}

With respect to the Ministerial Round Table communique 2017, the purpose of integrating education into SD is paramount and it's a global trend that shows the turning points of HEIs. The transformative role of HEIs in all development sectors is all about knowledge creation, transfer, translation, production and utilization to create innovative solutions for sustainability challenges. The significant role of HEIs in making development more productive and sustainable is now the pressing agenda for all nations including Somaliland signed up the SDGs in September, 2015. In all parts of the world, education should meet the needs of the present generation and, especially among youth who take charge of the future [19]. In this regard, HEIs are required to take due account of the three pillars of SD, which are; environmental protection, economic and social issues. Since, all levels of education are very important in social change, nevertheless, the focuses of this paper is transformation of HEIs for SD by structuring their programs in way that contributes to the targets of the SDGs at national level and beyond. ESD thus includes education for poverty alleviation, human rights, gender equality, cultural diversity, international understanding, peace and many more. However, these targets are the pressing concerns that more developing countries and other underdeveloped countries like Somaliland want to address so as to tackle down challenges posted the current SDGs.

UNESCO states that the mission of HEIs is to promote human rights, good governance, peace, security, equality and justice [20]. These pillars are the key factors that facilitate to achieve the targets of SDGs. Through their pivotal and influential role in society, universities are key stakeholders in achieving a sustainable future [21]. Transformative leadership in HE plays also a crucial role in elevating the importance of SDGs. While the basic philosophy of education is bond to transformation of human behavior, nonetheless education system should meet the social goals in relation to sustainability dimensions.

The current vision of HEIs in Somaliland ought to focus on quality, transformational change and create values required for creating a sustainable society. For HEIs undertake a positive societal transformation, collaboration of other stakeholders are indispensable including the government support, R\&D investment of the private sector and other offers of the professional bodies are very instrumental. HEIs should act as link between the communal needs, the marketplace demand guided by the governmental policies through synergizing institutional efforts. I begin by providing an overview of transformational change with an emphasis on how such efforts can be utilized to facilitate interdisciplinary initiatives. The national development goals of Somaliland should focus the basic needs through domestic education financing and improving the quality of 
the education system of all levels. At present, almost all institutions of higher learning adopted the slogan of Transforming Higher Education for Sustainable Development, which is the responsive to the UN initiative of ESD. Interlinking the trajectory of education and national goals with a proper strategic framework would ensure to realize the national development goals. The Nexus between development goals and the education system together should deal with the dynamics of both the physical/biological and socio-economic environment and human (which may include spiritual) development [22].

ESD is explicitly mentioned in Target 4.7 of SDG4, which aims to ensure that all learners acquire the knowledge and 21st century skills needed to uphold SD and is understood as an important means to achieve all the other 16 SDGs (UNESCO, 2017). As such, HEIs act as the central axis and an effective multiplier for achieving the targets within the SDGs. The recent development plan of Somaliland is based on the global targets within the SDGs but no attempts were made to clarify HESD and its implications for achieving the target set. Therefore, the following framework highlights the tensions between a developing agenda and the role of HEIs toward contributing to the SDGs.

The following framework links HEIs and the triple helix of SDGs. ESD touches several disciplines, such as environment, biology, medicine, nutrition, agronomics, geography, engineering, architecture, citizenship, sociology, psychology, political science, history, law, economics and business. Given the breadth and the interconnectedness of the SD agenda, the SDGs cannot be pursued in isolated. Therefore, contributions of HEIs to achieving SDGs are explicit and paramount. Though the proposed framework has not been empirically analyzed, it builds upon the prior conceptual frameworks for ESD and could be used as a generic notion in HEIs and SDGs. Furthermore, the framework demonstrates the bigger picture about the interconnectivity of national education and achieving the targets within the SDGs based on the national priorities.

There are many frameworks and indices already developed while there limited literature on the Somaliland context in this regard. For Somaliland to achieve basic targets of SDGs it requires transformative HE leadership, alongside with private sector, government and civil society, as the private sector holds much of the advanced technologies and management systems that will be essential for the success of the SDGs.

Now there is a wide consensus that HEIs do have an irreplaceable and pivotal role in ensuring SDGs. The following framework draws the bigger picture about interlinkages between HEIs and SDGs. 


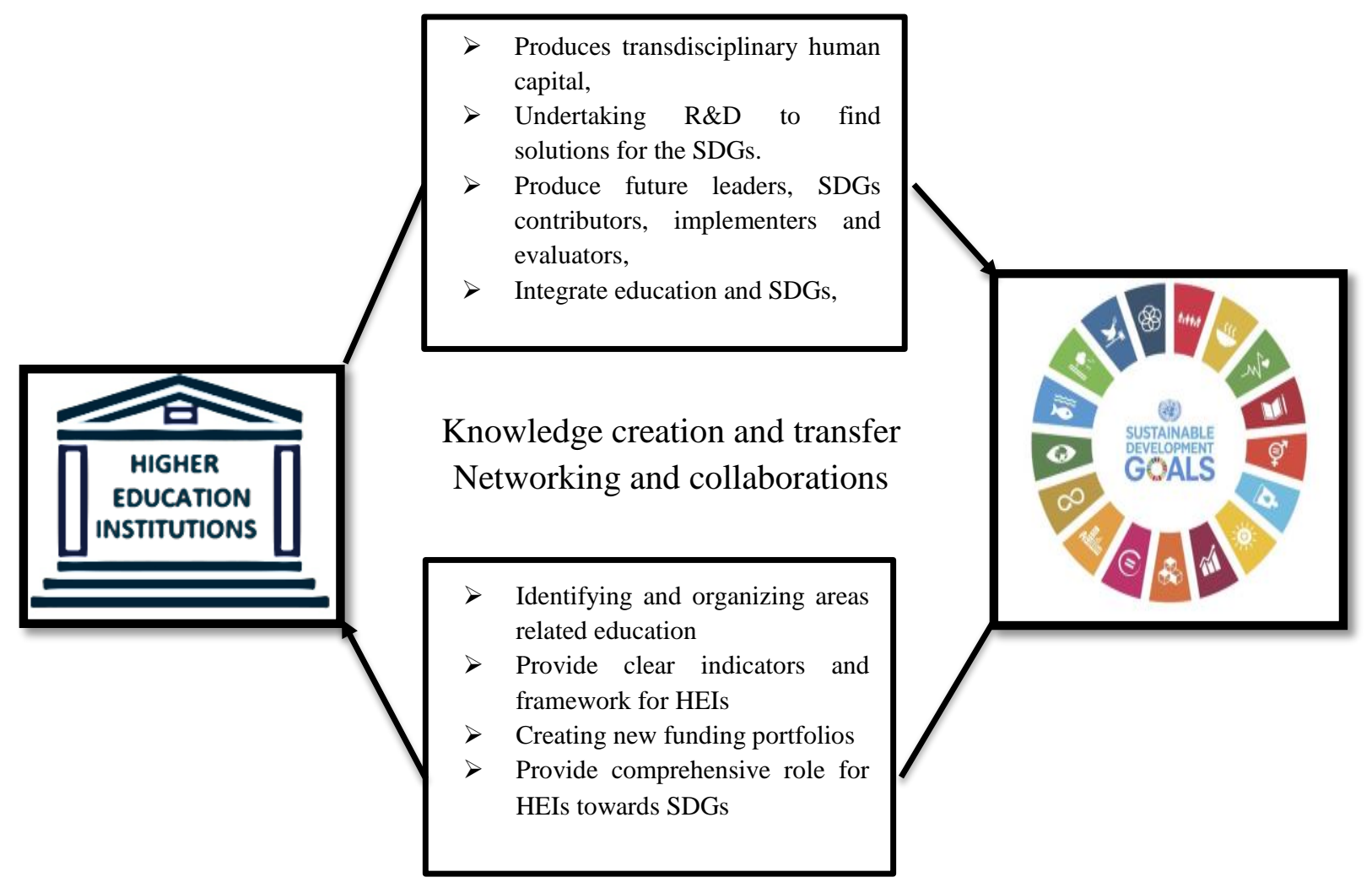

The aforementioned integrated framework sets out common SDGs and HEIs roles including; intellectual capital development and leveraging $R \& D$ and STI provision into the various aspects of sustainability. HEIs in Somaliland have not yet responded and initiated relevant policies, and strategies aimed at transforming universities for sustainability. Although, a shift from one stage to another stage should meet preconditions in this regard, absorptive capacities of public and private institutions are not yet in place. Therefore, any plans set including the current Somaliland development goals will remain a document on the shelf and the progress will not also be measurable with relevant indicators are in place. For HEIs to be more transformative rather than trans-missive, the framework proposes the following common goals:

1. Institutionalizing SD principles across HEIs' programs;

2. Introduce a common ESD strategy outlining what the Somaliland is trying to achieve and the guiding principles needed to achieve it;

3. Identifying the national education goals for Somaliland develop plan in relation to achieving the SDGs;

4. Aligning HEIs with sustainability dimensions and setting both responsive and rational goals for transformational change;

5. Designing suitable indicators to monitor the progress and evaluate the impact; 
Furthermore, the framework presented above is nexus and pivotal of HEIs and SDG. The framework is strongly suggesting the synergy between HEIs and SD which has been proved by some empirical evidence in the prior scholarships. As result of this, Somaliland education system should rigorously structure their portfolios so that issues related to sustainability will be incorporated into their curriculum. Positioning HEIs a leading role in the implementation of SD by designing their leadership structures and by establishing sustainable resources for the universities is indispensable. The proposed framework also came up with the following concepts, there are undoubtedly among others:

1 Transformative education rather than merely transmissive education to equip learners with capacity to address sustainability challenges. Rather than being a one-way process of teaching, it must be more collaborative with a strong emphasis on critical thinking ability and creativity;

2 A robust emphasis on efficiently undertaking inter and transdisciplinary R\&D including community engagement activities;

3 Societal problem-solving orientation in education and research through an interaction through multiple interfaces to be pertinent to societal goals. As a result, students must be able to deal with the complexities of real problems and the uncertainties associated with the future;

4 Establishing institutional ecosystem that can tap into varied expertise around the campus to efficiently and meaningfully share resources;

5 Transformative leadership that promotes transformational change and value creation accompanied by accountability and public acceptance, which are aim to a long-term transformation of the HEIs and are willing to be responsive to social dynamics;

With respect to UN Declaration on ESD, HEIs recognized to respond to the sustainability challenges, and develop a key competencies in the areas of S\&T and R\&D and therewith of one their core capacities. For this purpose, a paradigm shift and HEIs turning points are necessary, which moves away from merely trans-missive to transformative culture based on the SDGs. Furthermore, cascading skills for development as a new learning culture is one of the fundamental principles of transforming HESD. This would enable to provide grandaunts with the desired skills to contributing the SDGs and developing national intellectual capacity as a sustainable asset. In Somaliland context, the need for quality of basic education is paramount, and reestablishing the existing universities toward sustainability is now a national issue. On top of this, good governance, envisioning and transformative leadership within HEIs are the major concern in Somaliland context. The goal in this case, in addition is to alleviating education standards; capacitating HEIs for inclusive and holistic development, enabling universities to be able to cope with complex social, economic and environmental challenges. HESD is a process which considers the requisites of transformative education including the following strategic points: 
1 Societal orientation; learning for SD is always also societal learning. Learning takes place in real-life situations which question and change societal living.

2 Economical orientation; the focus of education is change in skills by obtaining relevant key competencies; this requires a transactional framework that constitutes inventories of competencies.

3 Environmental orientation; learning through the context and relating education to Environmental issues should be taken into consideration for developing ecological competencies.

For education to be transformative, Somaliland education system need to be reengineered and set goals and strategies that help HEIs to become more responsive to social, economic and environmental issues. Though improving the holistic quality of education at the transmissive stage would be a major concern, yet there are potential challenges ahead for transforming the current education system. This review paper is spotlighting the need for education shifting, the current trend of the universal education and how it will go in the future. The three pillars of sustainability as indicated above are the most challenging triple constrains that HEIs are expected to contribute through aligning their curriculum with sustainability dimensions.

\section{Discussions}

In this section, the policy document reviews and prior research works answered importance of transforming HESD and assures many gaps within ESD particular in the universities. ESD is both multi-sectoral and cross-cutting agenda and it positions education the central axis for sustainability aspects. Through their pivotal and significant role in society, HEIs are key stakeholders in contributing to the targets of SDGs [23]. As respected thought HEIs leaders have the opportunity to elevate the importance of SD through scholarly and public discourse. As knowledge and skills providers, universities should cement framework for the community in a way that organizes efforts of the other stakeholders and guides them toward contributing to the sustainable future. Conversely, in Somaliland context, universities lack a common platform within the national strategic plan that integrates HEIs' capacities into the development targets [23]. In addition, universities have the opportunity to provide their communities with graduates who have the knowledge and skills necessary to help transform their workplaces and live as responsible global citizens [24].

UNESCO (2006) pinpoints four plunges of (ESD): (1) improving access to quality basic education; (2) reorienting existing education to address sustainability; (3) developing public understanding and awareness; and (4) providing training programs for all sectors of private, governmental, and civil society. These four provisions are becoming fundamental core functions of HEIs, yet in Somaliland context, education remained to be only transmissive, though the quality and relevance of education programs is questionable. Similarly, Graz declaration in 2005 concluded and emphasized that university should confront the challenges and opportunities of 
sustainability through; (1) teaching and learning, (2) Research and Development and (3) internal and external social responsibilities.

Though HE creates social, economic and environmental impact and again it has the highest multiplier impact in this regard. The following table highlights HEIs related SDGs.

\begin{tabular}{|l|l|}
\hline Related Sustainable Development Goals \\
\hline Goal 04 & $\begin{array}{l}\text { Ensure inclusive and equitable quality education and promote life-long learning } \\
\text { opportunities for all }\end{array}$ \\
\hline Goal 09 & $\begin{array}{l}\text { Build resilient infrastructure, promote inclusive and sustainable industrialization and } \\
\text { foster innovation }\end{array}$ \\
\hline Goal 12 & Ensure sustainable consumption and production systems \\
\hline Goal 16 & $\begin{array}{l}\text { Promote peaceful and inclusive societies for sustainable development provide access to } \\
\text { justice for all and build effective, accountable and inclusive institutions at all levels }\end{array}$ \\
\hline Goal 17 & $\begin{array}{l}\text { Strengthen the means of implementation and revitalize the global partnership for } \\
\text { sustainable development }\end{array}$ \\
\hline
\end{tabular}

The table outlines the key features of SDG4-Education 2030 and the global commitments expressed in the SDG4 targets as articulated in the Incheon Declaration and the Education 2030 Framework for Action. The guide also examines the implications of translating these global commitments within, and through, national education development efforts. Yet, the current education system in Somali context remains poorly transmissive. In order to be truly transformative, higher education needs to transform itself.

On top of that, to achieve the targets of SDGs in Somali context is both challenging and speculation due to lack of good governance and transformational leadership in education providers. Targets of SDGs have three pairs of great importance as prerequisite: i) good governance and inclusive politics led by transformative and envisioning leadership; ii) peace and security; and iii) structural and cultural stability.

There are promising signs that universities around the world are responding to these opportunities and beginning to engage in activities related to SD, whether through campus "greening", development of special courses on sustainability, or offering collaborative research opportunities. But what is really required in Somaliland HE system is to restructuring and reorienting through integrating programs into the SDG at national level. Considerable scholarships on ESD highlighted approaches to integrating SDGs into teaching and learning [25].

This paper is arguing that transformational change within universities particularly in structural and operational organizations could be a strategic shifting from transmissive to transformative education. Rather than looking at individual universities in Somaliland, the focus of this paper is the holistic perspective on the transformations that would enable HEIs to more rapidly shift the course. Over the years, since 1970s, world universities went through significant evolutions in their roles, inputs, outputs and their leadership. For instance, $1^{\text {st }}$ generation university and the current $5^{\text {th }}$ universities are very different in their provisions, capacities, and outputs and of course 
their leadership approach. What has been marked universities as $1^{\text {st }}$ and future generation universities are the extent to which a university produces, translates, and utilizes knowledge toward addressing social, economic and environmental dimensions of sustainability[26].

As result of this, Somaliland universities are far behind to benchmark themselves to $1970 \mathrm{~s} 1^{\text {st }}$ generation universities while the current and the future universities are more oriented in transformation and sustainability. Therefore, in response to growing concerns of the community about sustainability challenges, universities in Somaliland should move towards a sustainable future by implementing programs of education for ESD.

\section{Conclusions}

This paper is aimed to explore the nexus between HEIs and SDGs through both transmissive and transformative perspectives of education. The trend of HE went through different stages from teaching to transformational approach. The prior research works have shown a great interest on ESD and it has been spotlighted the interconnectivity of HE and SDGs. While other scholarship works made their conclusions in connection to the UNESCO proposition of ESD and the role of universities in achieving SDGs. Bearing in mind the interactive effects between the trends of SD, HE, and SD-HE, especially under the influence of Rio + 20, shows that HEIs are taking a new role under the influence of SDGs. According to the review of literature and other policy documents reviewed indispensably placed ESD as the soul of the SDGs and has been recognized as key pillar towards achieving the vision of 2030. In this regard, the notion of ESD considers HEIs as an integral part in the strategic shifting from transmissive to transformative education. Education shift is a collective efforts and cooperation amongst the universities and the other stakeholders including the government and private business sectors, while civil society organization would play an integral role if they are properly engaged with.

With respect to the global agenda and the synergy that has been inspired within ESD brought about the current transformational change of many universities across the developed and the developing world, though a lot challenges are yet ahead. However, some countries like Somaliland/Somalia, the concept of higher education for sustainable development is not in the national agenda. Despite the fact that the government focuses primary education which is always an important element in HDI, yet it needs transformational change in relation to the SDGs.

The paper provided herein illustrated how to advance the interdisciplinary approach in education for sustainable development, in alignment with Somaliland National Development Goals. Thus education is to be considered as a key agent of development, either as a way of developing human capacity, increasing the skilled workforce for modernization, or as a matter of personal freedom, developing capability and empowerment. With regards to learning content such as curricula, the aspects of sustainability and other relevant thematic areas are the present issues that need be addressed and incorporated into Somaliland education system. 
Education must therefore address key issues such as climate change, poverty and sustainable production. ESD promotes the integration of these critical sustainability issues in local and global contexts into the curriculum to prepare learners to understand and respond to the changing world. ESD aims to produce learning outcomes that include core competencies such as critical and systemic thinking, collaborative decision-making, and taking responsibility for present and future generations.

In order to deliver such diverse and evolving issues, Somali education system should adapt an innovative pedagogy, encouraging teaching and learning in an interactive, learner-centred way that enables exploratory, action-oriented and transformative learning. Learners are enabled to think critically and systematically develop values and attitudes for a sustainable future. The present traditional single-directional delivery of knowledge without any standards is benchmark is no longer sufficient to inspire learners to take action as responsible citizens. Building the capacity of academia and policy support at Somali education system will help drive these changes in transforming universities for sustainability. Empowered youth and local communities interacting with education institutions become key actors in advancing SDGs.

In the final conclusion, this review paper underscores four clusters of ESD as the basic principles and sets of universal goals including; i) improving access to quality basic education; ii) reorienting existing education to address sustainability aspects; iii) developing public understanding and awareness; and iv) providing training programs for all sectors of private, governmental, and civil society.

\section{ACKNOWLEDGEMENT}

First and foremost, I would like to thank to IsDB for sponsoring me during my research career building in the academia network. Another thank goes to my peers who always appreciate my publications in the HE domain, Dr. Idiris Aden Ali, Muse Mohamed Dirie and Mohamed Sulub.

\section{REFFERENCE}

1. Stewart, M., Transforming Higher Education: A Practical Plan for Integrating Sustainability Education into the Student Experience. Journal of Sustainability Education, 2010. 1: p. 1-13.

2. A. Beynaghi, M., R. Maknoon, T. Waas, M. Mozafari, J. Huge, W. Leal Filho, Towards an orientation of higher education in the post Rio +20 process: How is the game changing? w ww .elsevier .co m /loc ate/fu tu r es, 2014: p. 49-67.

3. Blaze Corcoran, P. and K. Chacko Koshy, The Pacific way: sustainability in higher education in the South Pacific Island nations. International Journal of Sustainability in Higher Education, 2010. 11(2): p. 130-140.

4. Svanström, M., F.J. Lozano-García, and D. Rowe, Learning outcomes for sustainable development in higher education. International Journal of Sustainability in Higher Education, 2008. 9(3): p. 339-351. 
5. Nohooji, E.F.A.R.S.H.M.M.M.R., Using system dynamics to develop education for sustainable development in higher educationwith the emphasis on the sustainability competencies of students. Technological Forecasting \& Social Change, 2016: p. 307-326.

6. Sachs, J.D., From millennium development goals to sustainable development goals. The Lancet, 2012. 379(9832): p. 2206-2211.

7. Wals, A.E., Sustainability in higher education in the context of the UN DESD: a review of learning and institutionalization processes. Journal of Cleaner Production, 2014. 62: p. 8-15.

8. Ballantyne, R. and J. Packer, Promoting environmentally sustainable attitudes and behaviour through free-choice learning experiences: what is the state of the game? Environmental Education Research, 2005. 11(3): p. 281-295.

9. Holley, K.A., Interdisciplinary Strategies as Transformative Change in Higher Education. Innov High Educ, 2009. 34: p. 34:331-344.

10. Robert, K.W., T.M. Parris, and A.A. Leiserowitz, What is sustainable development? Goals, indicators, values, and practice. Environment: science and policy for sustainable development, 2005. 47(3): p. 8-21.

11. Madar, M.J., M.D. Subari, and S.M.S. Baqutayan, Incorporating Science and Technology in Higher Education into Strategic Planning for Sustainable Development in Somaliland. Journal of Science, Technology and Innovation Policy, 2018. 3(2).

12. Milutinović, S. and V. Nikolić, Rethinking higher education for sustainable development in Serbia: an assessment of Copernicus charter principles in current higher education practices. Journal of cleaner production, 2014. 62: p. 107-113.

13. Slobodan Milutinovi, V.N., Rethinking higher education for sustainable development in Serbia: an assessment of Copernicus charter principles in current higher education practices. Journal of Cleaner Production, 2014(62): p. 107-113.

14. Grindsted, T. and T. Holm, Thematic development of declarations on sustainability in higher education. 2012.

15. Armah, B. and S.-J. Baek, Can the SDGs promote structural transformation in Africa? An empirical analysis. Development, 2015. 58(4): p. 473-491.

16. Dongjie Niu, D.J.a.F.L., Higher education for sustainabledevelopment in China. Higher education for sustainable development, 2010. 11(2): p. 153-162.

17. Scheyvens, R., G. Banks, and E. Hughes, The private sector and the SDGs: The need to move beyond 'business as usual'. Sustainable Development, 2016. 24(6): p. 371-382.

18. Johnston, A., Higher Education for Sustainable Development. 2007, Organisation for Economic Co-operation and Development (OECD).

19. Ahunanya Stella, O.T.a.U.C., Incorporating Education for Sustainable Development into Strategic Planning of Higher Education Institutions in Lagos State of Nigeria. Journal of Emerging Trends in Economics and Management Sciences, 2010. 1(1): p. 46-50.

20. Dooris, J.O.a.M., Integrating health and sustainability: the higher education sector as a timely catalyst. HEALTH EDUCATION RESEARCH, 2010. 25(2): p. 425-437.

21. Cortese, A.D., The critical role of higher education in creating a sustainable future. Planning for higher education, 2003. 31(3): p. 15-22.

22. Buckler, G.A.H.H.C.C., Education for Sustainable Development at Manitoba Colleges and Universities, H.C.a.C.B. Written by Gabriel A. Huppé, Editor. 2013, The International Institute for Sustainable Development: The International Institute for Sustainable Development. 
23. Mohammed Madar, M.D.S., Shadiya Mohamed, Inter-institutional Framework towards Improvising SDGs in Somaliland: The Transformative Paradigm. International and Multidicipilinary Journal of Social Science 2017. 6(3): p. 307-329.

24. Silva, A.B.S.L.N., A Strategic and TransformativeApproach to Education for

Sustainable Development, in School of Engineering. 2013, Blekinge Institute of Technology: Sweden. p. 93.

25. Felgendreher, S. and Å. Löfgren, Higher education for sustainability: can education affect moral perceptions? Environmental Education Research, 2018. 24(4): p. 479-491.

26. Komiyama, H. and K. Takeuchi, Sustainability science: building a new discipline. 2006, Springer. 